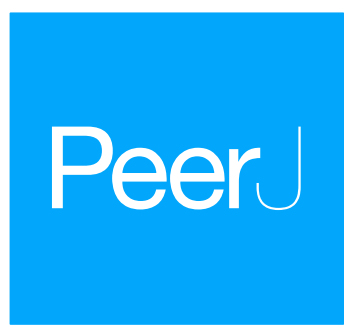

\title{
Distribution and status of living colonies of Acropora spp. in the reef crests of a protected marine area of the Caribbean (Jardines de la Reina National Park, Cuba)
}

\author{
Leslie Hernández-Fernández ${ }^{1,2}$, Roberto González de Zayas ${ }^{3}$, \\ Yunier M. Olivera ${ }^{1}$, Fabián Pina Amargós ${ }^{4}$, Claudia Bustamante López ${ }^{1}$, \\ Lisadys B. Dulce Sotolongo ${ }^{1}$, Fernando Bretos ${ }^{5}$, \\ Tamara Figueredo Martín ${ }^{4}$, Dayli Lladó Cabrera ${ }^{1}$ and \\ Francisco Salmón Moret ${ }^{6}$ \\ ${ }^{1}$ Marine Ecology, Coastal Ecosystem Research Center, Ciego de Avila, Cuba \\ ${ }^{2}$ Department of Tourism and Business, Máximo Gómez Báez University, Ciego de Avila, Cuba \\ ${ }^{3}$ Centro de Estudios Geomáticos, Ambientales y Marinos (GEOMAR), Ciudad de México, México \\ ${ }^{4}$ Environmental Advisors, Avalon-Marlin, Jardines de la Reina, Ciego de Avila, Cuba \\ ${ }^{5}$ Phillip and Patricia Frost Museum of Science, Miami, FL, USA \\ ${ }^{6}$ Coastal Dynamics, Coastal Ecosystem Research Center, Ciego de Avila, Cuba
}

\section{ABSTRACT}

The reef crests of the Jardines de la Reina National Park (JRNP) are largely formed by Acropora palmata, but colonies of A. cervicornis and the hybrid A. prolifera are also present. This study shows spatial distribution of colonies, thickets and live fragments of these species in the fore reefs. Snorkeling was used to perform the direct observations. The maximum diameter of 4,399 colonies of $A$. palmata was measured and the health of 3,546 colonies was evaluated. The same was done to 168 colonies of $A$. cervicornis and 104 colonies of $A$. prolifera. The influence of the location and marine currents on a number of living colonies of $A$. palmata was analyzed. For such purpose, reef crests were divided into segments of $500 \mathrm{~m}$. The marine park was divided into two sectors: East and West. The Caballones Channel was used as the reference dividing line. The park was also divided into five reserve zones. We counted 7,276 live colonies of Acropora spp. 1.4\% was A. prolifera, 3.5\% A. cervicornis and $95.1 \%$ A. palmata. There were 104 thickets of A. palmata, ranging from eight to 12 colonies, and 3,495 fragments; $0.6 \%$ was A. cervicornis and the rest $A$. palmata (99.4\%). In the East sector, 263 colonies (3.8\% of the total), six thickets (5.8\%) and 32 fragments (1\%) of A. palmate were recorded. In the same sector, there were 11 fragments (50\%) of A.cervicornis and two (2\%) colonies of $A$. prolifera. Health of $A$. palmata was evaluated as good and not so good in the study area. Health of $A$. cervicornis was critical and health of $A$. prolifera was good in all five reserve zones. There was a significant increase in the number of colonies from east to west $(\mathrm{X} 2=11.5, \mathrm{gl}=3.0, p=0.009)$. This corroborates the existence of an important abundance differences between the eastern and the western region of the JRNP. A negative relationship was observed between the number of colonies and the distance from the channel $(\mathrm{X} 2=65.0, \mathrm{df}=$ $3.0, p<0.001)$. The influence of the channel, for the live colonies of A. palmata is greater within the first $2,000 \mathrm{~m}$. It then decreases until approximately $6,000 \mathrm{~m}$, and

How to cite this article Hernández-Fernández L, González de Zayas R, Olivera YM, Pina Amargós F, Bustamante López C, Dulce Sotolongo LB, Bretos F, Figueredo Martín T, Lladó Cabrera D, Salmón Moret F. 2019. Distribution and status of living colonies of Acropora spp. in the reef crests of a protected marine area of the Caribbean (Jardines de la Reina National Park, Cuba). PeerJ 7:e6470 DOI 10.7717/peerj.6470 
no significant increase beyond. The orientation of the reef crests significantly influenced the abundance of the colonies $(\mathrm{X} 2=15.5, \mathrm{df}=2.9, p=0.001)$. The results presented here provide a baseline for future research on the status of the populations of Acropora spp., considering that there has been a certain recovery of the species A. palmata during the last 10-16 years. Given the current status of the populations of Acropora spp., conservation actions focusing A. cervicornis should be prioritized.

Subjects Ecology

Keywords Jardines de la Reina National Park,Cuba, Acropora palmata, Acropora cervicornis, Acropora prolifera

\section{INTRODUCTION}

The Jardines de la Reina Archipelago, established as the Jardines de la Reina National Park (JRNP) by the Executive Committee of the Council of Ministers of Cuba in 2010 (6803/2010), has marine and terrestrial ecosystems of high ecological values. Coral reefs are particularly important in the area. In the reef crests, Acropora palmata Lamarck, 1816; one of the most representative species of the Caribbean region (Bruckner, 2003), is relatively common. In the reef crests, we also observed colonies of A. cervicornis Lamarck, 1816 (HernándezFernández, Bustamante-López \& Dulce-Sotolongo, 2016) and A. prolifera Lamarck, 1816 (L. Hernández-Fernández, C. Bustamante-López \& L. B. Dulce-Sotolongo, 2016, personal observation) considered an F1 hybrid of the species A. palmata and A. cervicornis (Vollmer \& Palumbi, 2002). Zlatarski \& Martínez-Estalella (1980) described the distribution, variability, taxonomy and associated fauna of $A$. palmata and A. cervicornis in Cuba.

The genus Acropora is the most diverse reef building coral in the world (Wallace \& Rosen, 2006), Florida and the Great Caribbean (Jackson, 1992). This genus significantly contributes to the formation of islands and to coastal protection (Bruckner, 2002). The Atlantic/Caribbean has two species: A. palmata and A. cervicornis, and also the hybrid A. prolifera (National Marine Fisheries Service, 2014). A. palmata and A. cervicornis were generally the most abundant species in many reefs of the Caribbean. Their high growth rates have allowed these reefs to keep up with changes in sea level. In addition, due to their branching morphologies, they are an important habitat for other reef organisms (Acropora Biological Review Team, 2005), such as fishes, turtles, echinoderms, crustacean and mollusks (Bruckner, 2002). They also provide amazing scenic values for recreational diving.

Both, A. palmata and A. cervicornis, experienced abrupt declines in their populations in the early 1980s, substantially reducing coral cover and at the same time, their dead skeletons provided substrate for algal growth. Causes of mortality include hurricanes that have affected local populations Acropora spp. over the past 20-25 years; also the white-band disease, a more significant cause of mortality over large areas of the Caribbean region (Aronson \& Precht, 2001). Decline due to disease has been documented by other studies (Patterson et al., 2002; Muller et al., 2008; Fogarty, 2012, Muller, Rogers \& van Woesik, 2014). Such decline has also been attributed to temperature changes that have 
induced bleaching, physical damage caused by other extreme weather events (Acropora Biological Review Team, 2005), excessive nutrients, overfishing or a combination of these global and local threats (Jackson et al., 2014). A. palmata and A. cervicornis appear on the "IUCN Red List" as critically endangered (Aronson et al., 2008). In Cuba, A. palmata also suffered a massive mortality between the years 1987 and 1992 (Claro, 2007). The large-scale mortality of $A$. palmata affects reef biodiversity, as well as fisheries productivity (Álvarez-Filip et al., 2009).

While some studies have shown recovery of A. palmata (Rogers et al., 2002; Zubillaga, Bastidas \& Croquer, 2005; Schelten et al., 2006; Zubillaga et al., 2008; Muller, Rogers \& van Woesik, 2014; Larson et al., 2014), others have shown little or no recovery (Rodríguez-Martínez et al., 2014; Croquer et al., 2016; Miller, Kerr \& Williams, 2016). Alcolado et al. (2003), in a study conducted on the reefs of Cuba, observed high mortality of A. palmata in most of the sites along the northern and southern coasts, presumably caused by diseases such as white band, bleaching and white pox.

A thorough study showing the spatial distribution and status of the genus has not been carried out elsewhere in the JRNP, in spite of its importance, threats and current condition. The only reference was the work of Hernández-Fernández \& Bustamante-López (2017) on the status of A. palmata in four reef crests in the central region of the park. This study describes the distribution and status of live colonies of Acropora spp. in the fore reefs of the JRNP.

\section{MATERIALS AND METHODS}

\section{Study area}

The distribution and health of colonies, thickets and live fragments of A. palmata, A. cervicornis and A. prolifera were studied in the fore reef zone of the reef crests of the JRNP, which stretches off the southern coast of the provinces of Sancti Spiritus, Ciego de Ávila and Camagüey (Fig. 1).

\section{Monitoring}

The study was conducted in 2017, during the months of August and September. The methodology of Miller, Kerr \& Williams (2016), used to determine the abundance and status of Acropora spp. populations in the Florida reefs, was also used in this study.

To determine the distribution of colonies, thickets and live fragments of A. palmata, A. cervicornis and A. prolifera, a direct observation census (snorkeling) was conducted and documented using GPS. Two work teams of six divers were divided into three pairs. Each pair covered an area of up to 500 linear meters in the fore reef zone. The routes, similar to those of Miller, Kerr \& Williams (2016), were carried out in zigzags, perpendicular to the reef crest, covering the entire area where colonies, thickets or live fragment of Acropora spp. could be found.

The distances covered by each pair were marked with buoys found in most reef crests of the park. The GPSs were wrapped in nylon to prevent water damage and held in ring buoys. Five couples used GARMIN GPS (GPSMAP 78) and one of the couples used GARMIN (Etrex 20). To define a living colony, we considered what 




Figure 1 Location of study area; Jardines de la Reina National Park, Cuba.

Full-size

Williams, Miller \& Kramer (2006) proposed in the monitoring protocol for Acropora spp. established for the Caribbean area. "Thickets" were defined when it was not feasible to demarcate individual colonies. At least three points were taken into account to determine the size of the thickets. For fragments, pieces of the colonies were selected, namely broken branches of Acropora spp. on the substrate, lacking a defined base (Martínez \& Rodríguez-Quintal, 2012).

One member of each pair took the coordinates and the other described the health of the colony, thickets and fragment. This exercise was previously tested. The coordinates taken with the GPS and information gathered were entered into a database upon a daily basis. Spatial distribution was obtained with the program QGIS 2.18. Taking the Caballones Channel as reference, the study area was divided into two sectors (East and West) (Fig. 1).

The limits of the JRNP were taken into account for the distribution of fragments. To stratify our survey, we divided the study area into five zones (Figs. 2-4): Reserve Extreme West (REW), Reserve West (RW), Reserve Center (RC), Reserve East (RE) and Reserve Extreme East (REE). Based on Pina-Amargós et al. (2008, 2014), reserve enforcement follows this zone pattern: $\mathrm{RC}>\mathrm{RW}>\mathrm{RE}>\mathrm{REW}>\mathrm{REE}$, where RC has high protection, RW and RE moderate protection, and REW and REE are the least protected. In addition, based on a previous study by Hernández-Fernández et al. (2016), we took into account highly used diving sites and classified their use as low, medium and high intensity.

To determine the status of the Acropora spp. colonies, an evaluation was carried out using the criteria of Alcolado \& Durán (2011), consisting of a system of scales for the classification and recording of the condition of the benthos and ichthyofauna of the coral reefs of Cuba and the Greater Caribbean region. The following criteria 


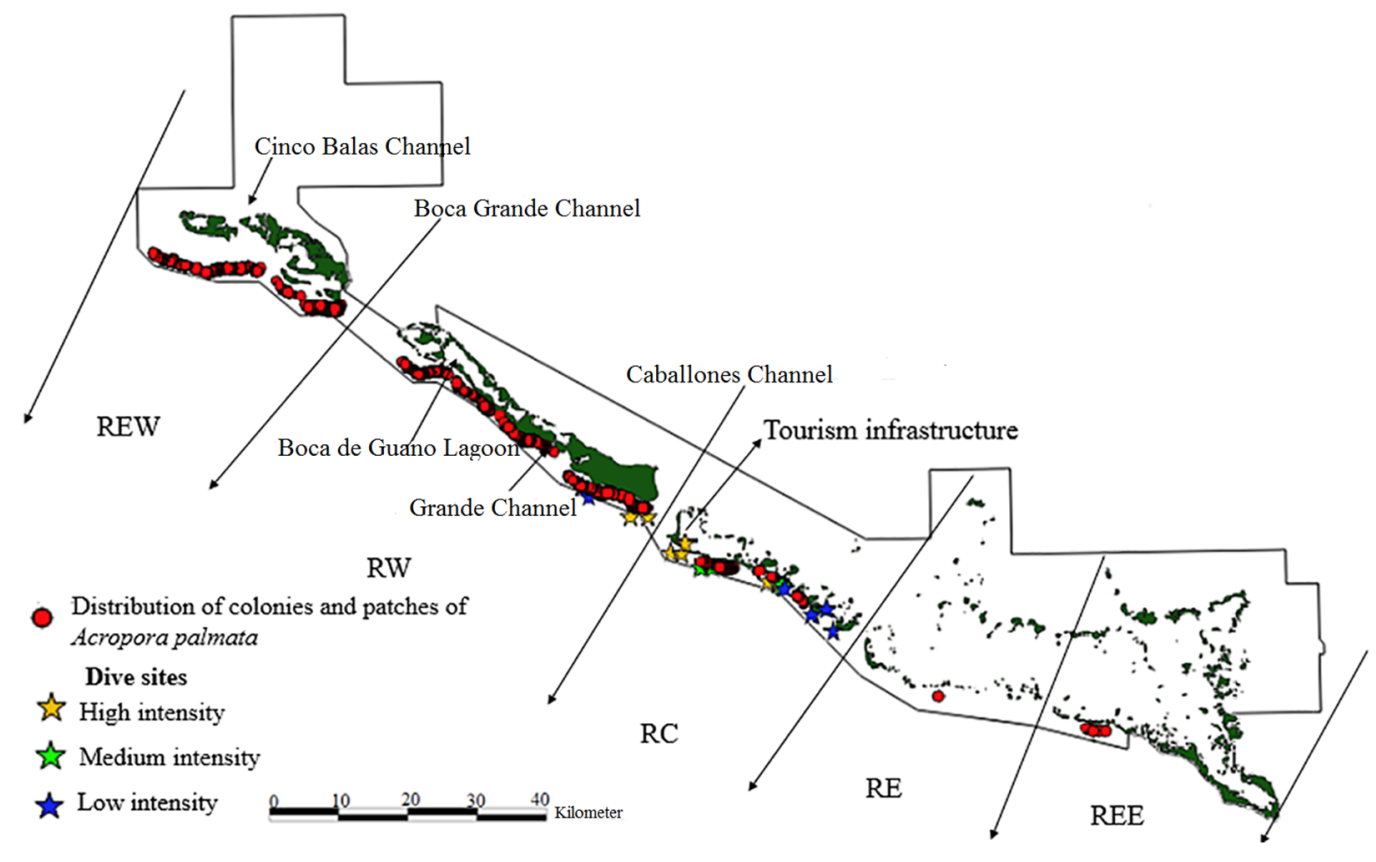

Figure 2 Distribution of live colonies and patches of Acropora palmata in Jardines de la Reina National Park, Cuba.

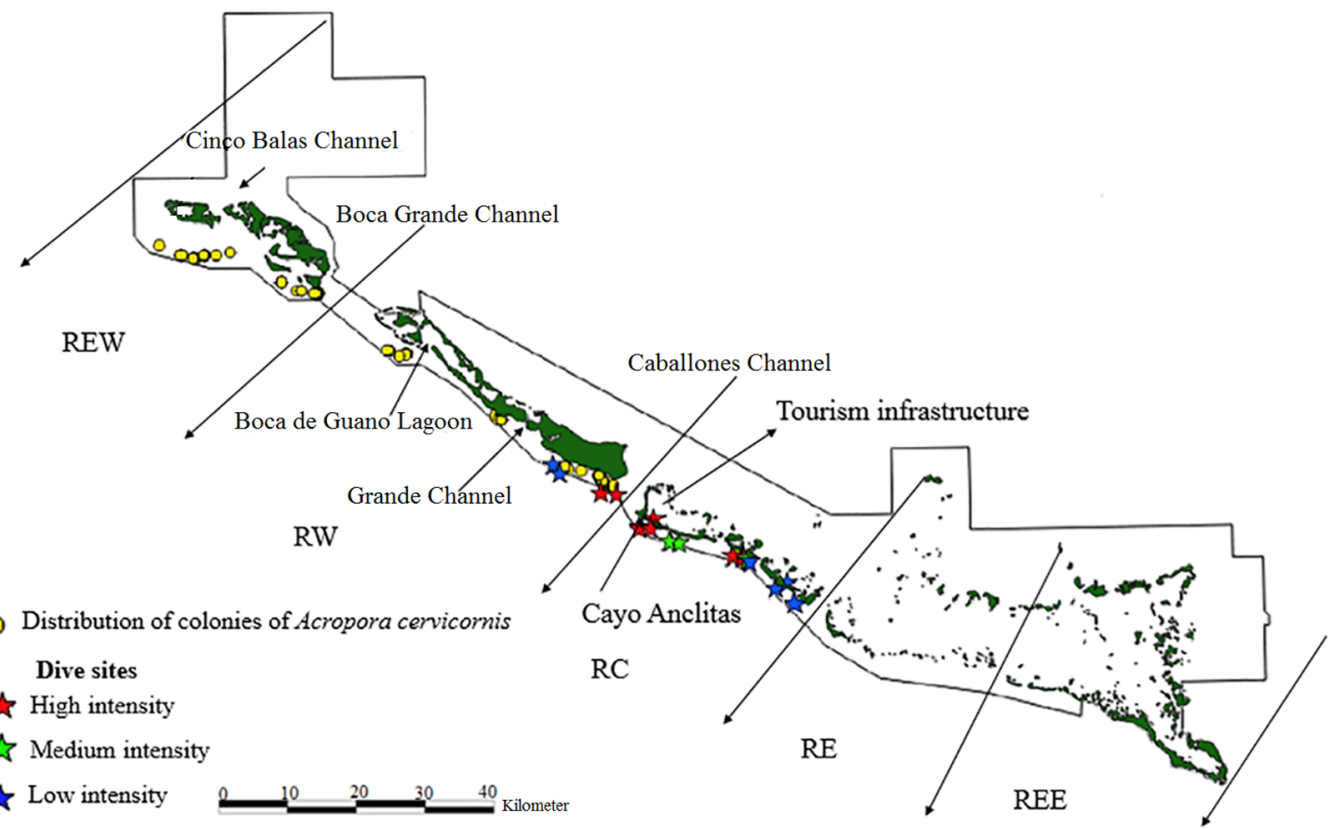

Figure 3 Distribution of live colonies of Acropora cervicornis in Jardines de la Reina National Park, Cuba. Full-size $\underset{0}{ }$ DOI: 10.7717 /peerj.6470/fig-3

was used: percentage of recent mortality $(\mathrm{RM})(\%)$ (critical: $>16$, poor: $8-16$, not good: 4-7.9, good: 2-3.9, very good: <2). RM shows coral reef status last year (McField \& Kramer, 2008). According to McField \& Kramer (2008), a reef s health is bad, and a 


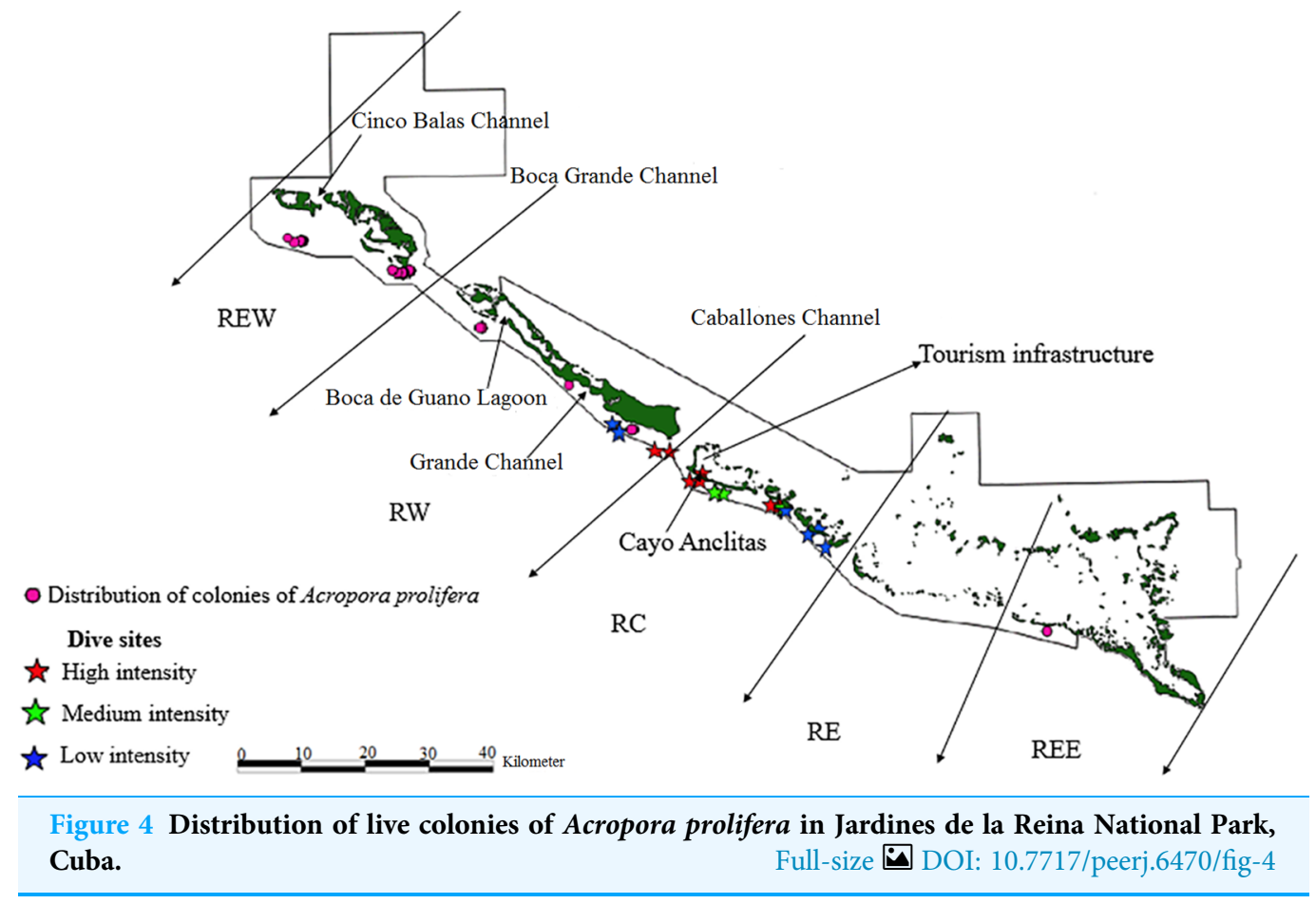

"Red Alarm" is recommended when RM is greater than $5 \%$, for which reason we used this criterion to evaluate the health status of Acropora colonies.

The status of 3,546 colonies of A.palmata (51\%), 168 of A. cervicornis (67\%) and 104 of A. prolifera (100\%) was evaluated. The percentage of old (OM) and RM and the presence of bleaching (BL), white pox disease (WPD) and white band disease (WBD) were recorded using ID cards (Weil \& Hooten, 2008). WPD and WBD were included in RM evaluation. The maximum diameter was also measured in 4,399 live colonies of A. palmata. Size ranges were established (between $10 \mathrm{~cm}$ and $50 \mathrm{~cm}$, between $51 \mathrm{~cm}$ and $100 \mathrm{~cm}$, greater than $100 \mathrm{~cm}$, greater and equal to $200 \mathrm{~cm}$ ). The maximum diameter was measured taking as a reference the tips of the most distal branches of each colony.

In order to analyze the influence of location and sea currents on the number of A. palmata colonies, reef crests were divided into $500 \mathrm{~m}$ segments. All recorded colonies were grouped talking into account the coordinates of the midpoint of their segment and treated as a response variable. The predicting variables were extracted from a detailed map using the Geographic Information System software QGIS 3.0.0 (QGIS Development Team, 2018). They included the coordinates of the segment midpoints, the shortest distance from these points to the mainland, to the closest channel eastward and the specific zone of the archipelago. To assess the potential influence of small-scale oceanographic processes, we explored the relationship between the distribution of the colonies and the distance to the western large channels. In Jardines de la Reina, the reef crests receive greater influence from marine currents out of the west due to their east-west circulation pattern in the south- central Cuban shelf (Claro, Lindeman \& Parenti, 2001). In addition, the slope of the line defined by the colonies in each segment was measured to evaluate the orientation of the reef crests with regard to the marine currents. 
Before applying any statistical model, data were reviewed to determine if a Poisson or negative binomial distribution were the most adequate to count colonies per segment. Then, collinearity between the covariates was evaluated using the analysis of variance inflation factors (VIF) in a generalized linear model with negative binomial distribution. To evaluate collinearity, the VIF> 2 (Graham, 2003) was used. The coordinate axes were highly correlated with each other, so the distance from the east end of the area to each segment was used as a substitute for both axes. Besides, the specific zone of the JRNP and the distance to mainland were also eliminated because they were highly collinear.

Because preliminary exploration indicated possible nonlinear relationships between the response variable and the covariables, generalized additive models (GAM) were applied. The final model used was a zero-truncated GAM (Zuur et al., 2009) with a negative binomial distribution, because it was the most effective one, based on the Akaike Information Criterion (AICc, Burnham \& Anderson, 2002). The decision to use the zero-truncated model was made because the response variable only included segments with A. palmata colonies (i.e. no segment with zero colonies was analyzed) and the assumption of a negative binomial distribution can be problematic, since it includes zeros within its range of possible values. If the response variable does not contain zeros, the estimated parameters and the standard errors obtained with a generalized model are likely biased (Zuur et al., 2009).

Graphs of model residuals against the predicted values, and latitude and longitude axes indicated that the model was fit. In addition, a Moran's I correlogram constructed with the residuals showed that the spatial autocorrelation observed in the raw data was adequately modeled. All analyses were carried out using the software R 3.4.3 (R Core Team, 2017), the zero-truncated GAM model was adjusted with the VGAM package (Yee \& Wild, 1996; Yee, 2015) and the Moran's I correlogram with the NFC package (Bjornstad, 2016).

Additionally, we explored the distribution pattern of $A$. palmata using the Besag's L-function (Besag, 1977), a transformation of Ripley's K-function, useful for classifying a point pattern as random, clustered, or regular (Baddeley, Rubak \& Turner, 2015). The inhomogeneous L-function was applied after testing the inhomogeneity assumption with the studentized permutation test of Hahn (2012) over 9,999 permutations (Tbar $=1001.5, p=0.6421)$. To test for significant deviations from a complete spatial randomness, we computed global confident intervals using the Loh's bootstrap (Loh, 2008; Baddeley, Rubak \& Turner, 2015), over nine simulations. The analyses were made in $\mathrm{R}$ using the spatstat package (Baddeley, Rubak \& Turner, 2015).

\section{RESULTS}

Surveys were performed along some 55 kilometers; approximately the linear distance of the reef crests of the JRNP, out of a total of about $120 \mathrm{~km}$, and roughly the distance from Cabeza del Este to Cayo Bretón. About two $\mathrm{km}$ were considered promontories (groups of colonies that build structure, but do not form crests) with Acropora spp. In the East sector of the JRNP, the reef crests stretched close to the Piedra Chiquita 


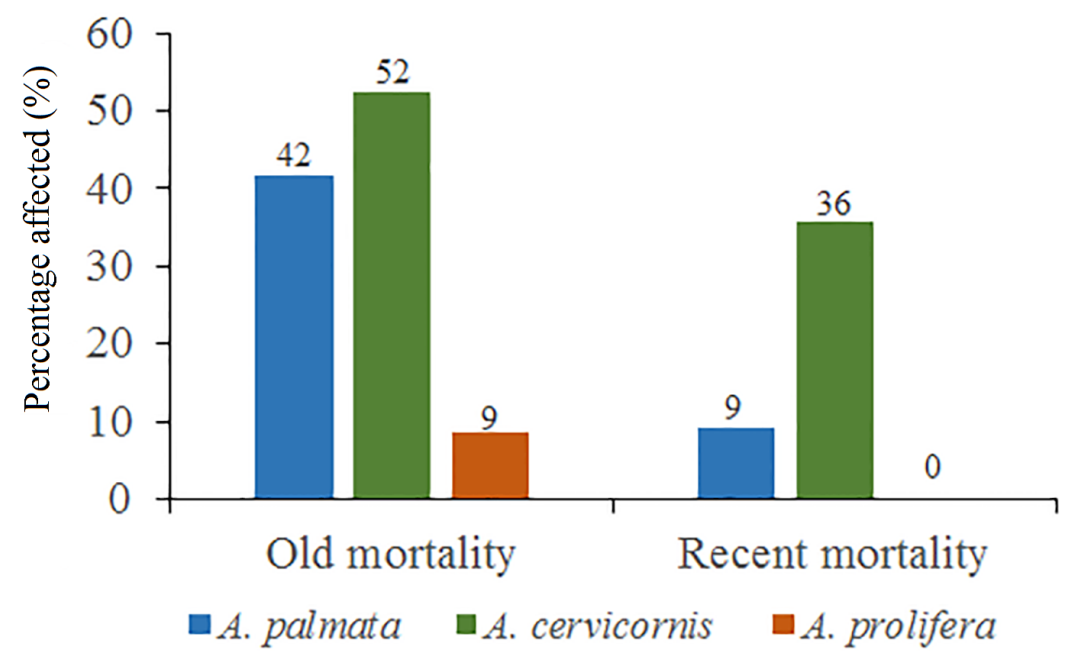

Figure 5 Percentage of old mortality and recent mortality in colonies of Acropora palmata, Acropora cervicornis and Acropora prolifera in Jardines de la Reina National Park, Cuba.

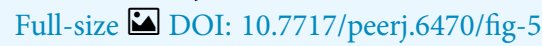

Channel (Fig. 1). From this point on, we observed isolated Porites spp. and abundant standing dead colonies of A. palmata.

Towards the West sector, the reef crests showed a much more consolidated formation than in the East sector and were not separated. For this reason, the largest number of colonies, thickets and live fragments of A. palmata, A. cervicornis and A. prolifera were counted in this sector. Nevertheless, abundant standing dead colonies of A. palmata were seen. The West sector comprises RE, REW and only four diving sites (two with high and two with low diving intensity) (Figs. 2-4).

There were 7,276 live colonies of Acropora spp., of which 104 (1.4\%) were A. prolifera, 252 A. cervicornis (3.5\%) and 6,920 of A. palmata (95.1\%) (Figs. 2-4). There were 104 thickets of $A$. palmata, formed by 8-12 colonies, 3,495 fragments, 22 of which were A. cervicornis and the rest A. palmata (99.4\%). In the East sector of the JRNP, only 263 colonies of $A$. palmate (3.8\%), 6 thickets (5.8\%) and 32 fragments of A. palmata (1\%) were recorded. In the same sector, only two colonies of $A$. prolifera (2\%) and 11 fragments of $A$. cervicornis (50\%) were found.

Regarding A. cervicornis, $26.2 \%$ was affected by BL and $0.6 \%$ by WBD. This species showed a high percentage (52\%) of OM (Fig. 5) and was only at RW and REW. The highest OM was observed in RW (46.5\%), while in REW, it was 7.4\%. RM affected $34.6 \%$ of the colonies in RW (24.4\% BL and $0.6 \%$ WBD). The status of A. cervicornis was critical, as $30.2 \%$ of the colonies were affected by RM (over 16\%). In RW, alarm bells should be rung for this species.

Of the 104 colonies of $A$. prolifera, only $9 \%$ were affected by OM (Fig. 5) and no diseases nor RM were detected, suggesting that A. prolifera is in very good health. Only $2 \%$ of $A$. prolifera colonies were affected by BL.

Of the 3,546 A. palmata colonies evaluated, $6 \%$ was affected by BL, $1.3 \%$ by WPD and $0.3 \%$ by WBD. The OM was high in A. palmata colonies (Fig. 5), with greater mortality 


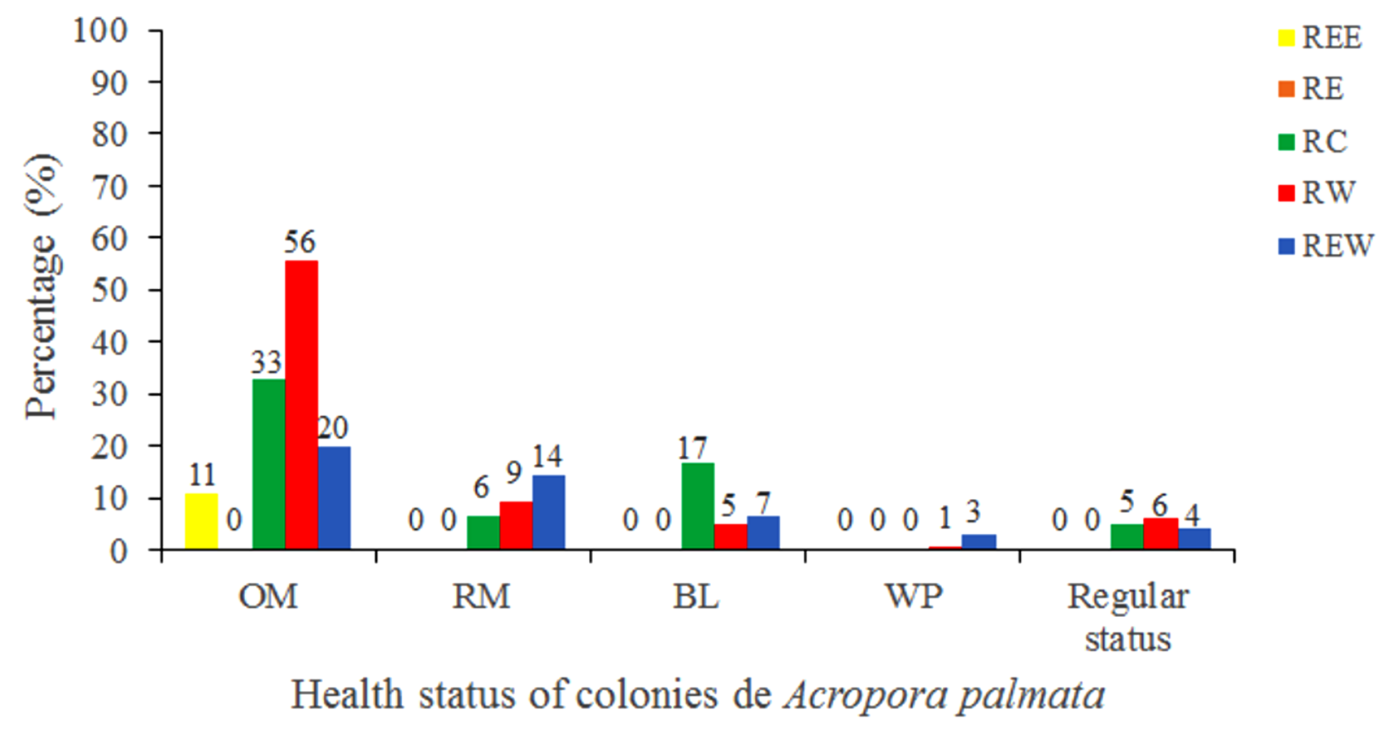

Figure 6 Health status of colonies of Acropora palmata, in five reserve zones, in Jardines de la Reina National Park, Cuba. OM: Old Mortality; RM: Recent Mortality; BL: Bleaching; WPD: White Pox Disease. Full-size $\underset{0}{0}$ DOI: 10.7717 /peerj.6470/fig-6

(56\%) in RW, followed by RC (33\%). Colonies in REW were more affected by RM and WPD. The negative effect of BL was greater in RC (Fig. 6). The health status of A. palmata was not good in RC, RW and REW (between 4\% and 7.9\%) zones and good in RE and REE. This species could be in "Red Alarm" in the RC and RW zones. The maximum diameter of the majority of $A$. palmata colonies (63.5\% measured) ranged from 0 to $100 \mathrm{~cm}$ (Fig. 7).

The zero-truncated GAM with negative binomial distribution showed that the number of $A$. palmata colonies varied significantly with regard to changes in the three predicting variables evaluated. Starting from the eastern end of the sampling area, a marked increase in the number of colonies was observed westward $(\mathrm{X} 2=11.5, \mathrm{df}=3.0$, $p=0.009$, Fig. $8 \mathrm{~A}$ ), which corroborates the existence of a significant difference between the East and West sectors of the archipelago. In addition, there is a negative relationship between the number of colonies and the distance to the channels $(\mathrm{X} 2=65.0, \mathrm{df}=3.0$, $p<0.001$, Fig. $8 \mathrm{~B}$ ). The influence of the channels is greater within the first $2,000 \mathrm{~m}$ (from east to west), where colonies are more abundant; abundance decreases up to approximately $6,000 \mathrm{~m}$, followed by a non-significant increase beyond the latter distance. Finally, the orientation of the reef crests significantly influenced abundance (X2 $=15.5$, $\mathrm{df}=2.9, p=0.001$, Fig. $8 \mathrm{C}$ ). When the reef crests have a horizontal position in regard to the coordinate axes (zero slope), the number of colonies increases significantly when compared to reef crests rather vertical to the axes.

The spatial analysis allows us to graphically examine the distribution patterns of A. palmata colonies. The aggregated pattern over a scale of $4,000 \mathrm{~m}$, has a stronger tendency in the first 1,000 $\mathrm{m}$ (Fig. 9). The shaded area in the graph represents a 95\% confidence interval for the estimated function, using Loh's bootstrap (Nsim $=9,999)$, and the dashed red line is the theoretical inhomogeneous L-function for a Poisson 


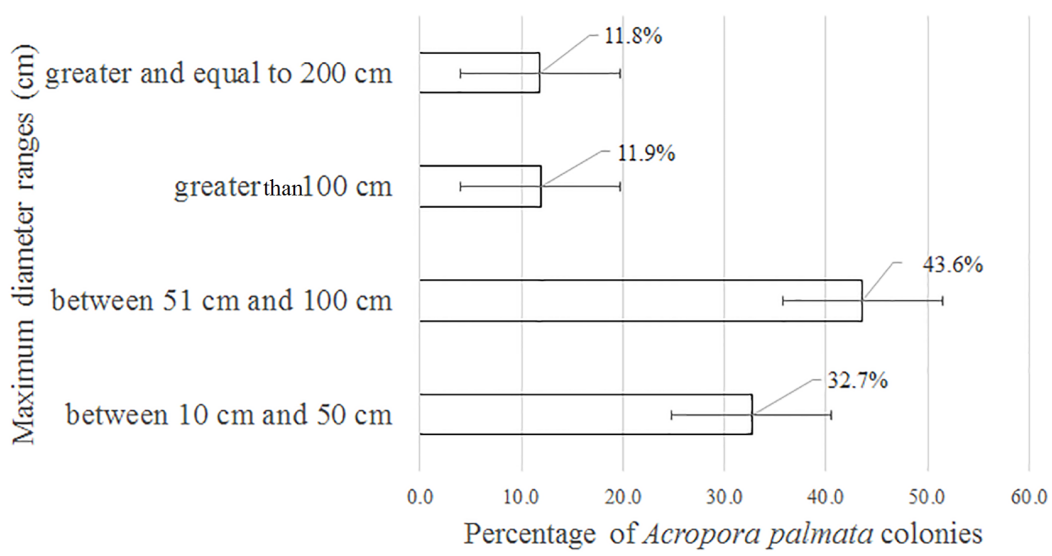

Figure 7 Maximum diameter ranges in Acropora palmata colonies in Jardines de la Reina National Park, Cuba. Full-size $\underset{0}{0}$ DOI: 10.7717 /peerj.6470/fig-7

Process (completely spatially random pattern). The higher curve for the estimated inhomogeneous L-function in respect to the theoretical function indicates a significant aggregated pattern in the distribution of A. palmata colonies.

\section{DISCUSSION}

The methodology used to understand the distribution and condition of the live colonies of Acropora spp. in this study, opens a new approach to marine cartography, allowing for greater precision while assessing changes in the populations (recovery or deterioration) over time (Devine, Loomis \& Rogers, 2002). According to Miller, Kerr \& Williams (2016), this methodology more efficiently shows the distribution of colonies and live thickets of Acropora spp. In this case, the fragments were also taken into account, because they play an important role in the maintenance of local populations and the formation of new colonies (Jackson, 1977). Our study lays the foundations to follow-up the living fragments recorded and their regeneration capacity in the JRNP. As stated by Martínez \& Rodriguez-Quintal (2012), the presence of fragments suggests that asexual reproduction may be the principal mechanism of $A$. palmata to maintain and expand its population in the JRNP, allowing the new colonies to be distributed in thickets around the living parent colonies. However, Roth, Muller \& van Woesik (2013) stated that the coral fragmentation may indicate the presence of unfavorable environments, since high fragmentation rates give the false impression of expanding and diversifying populations, when populations may be simply cloning.

The decline in coral abundance in the Caribbean region is greatly due to the dramatic loss of Acropora. Acroporid populations have declined 80-90\% throughout the Caribbean and the Western Atlantic since the late 1980s (Bruckner, 2002). Decline of Acropora populations also occurred in Cuban coral reefs between 1987 and 1992 (Claro, 2007). Contrary to the Acropora decline in the Great Caribbean (due to WBD), Bruckner (2002) and Claro (2007) found that in the southern coast of Cuba, Acropora populations showed low evidence of mortality due to WBD (Rey-Villiers et al., 2016). 



Figure 8 Results of truncated zero GAM applied to Acropora palmata colonies respective to geographical position. (A) The distance from the Eastern limit of the study area. (B) The distance to the channel closest to the East of the reef crests. (C) The slope (orientation) of the reef crests. The data was analyzed with a zerotruncated generalized additive model (GAM) with a negative binomial distribution. The solid line indicates the smoothed trend and the dashed lines \pm 2 the standard error. Full-size $\emptyset$ DOI: $10.7717 /$ peerj.6470/fig-8

More colonies, thickets and live fragments of Acropora spp. have been counted towards the West sector of the JRNP. This could be due to the topographic differences of the archipelago in both sectors. Probably, the east-westward orientation of the archipelago, 


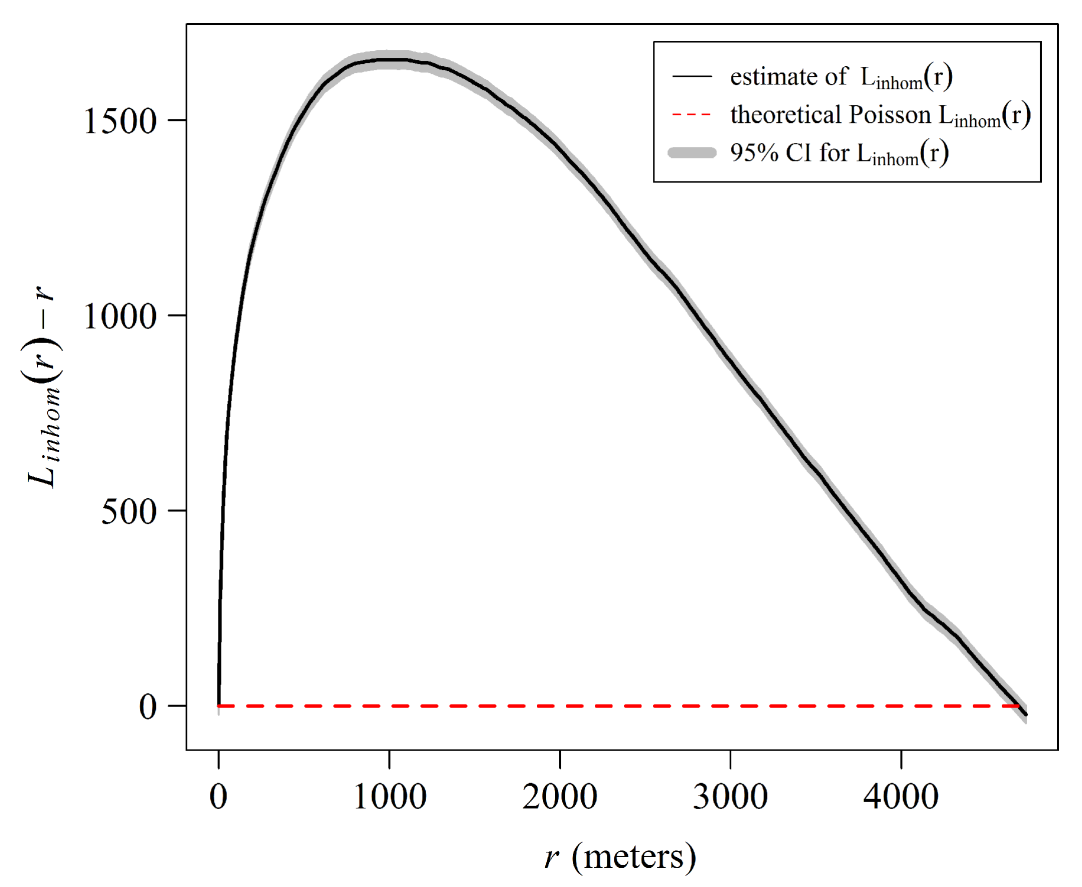

Figure 9 Estimate of the centered inhomogeneous L-function (solid line) for the distribution patterns of Acropora palmata colonies in Jardines de la Reina National Park, Cuba.

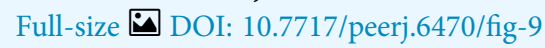

according to González de Zayas et al. (2006), can be an indication of the movement and deposition of sediments and even of the age of the reef crests, the easternmost ones being the oldest. Another observation that could explain the spatial distribution of A. palmata is that the easternmost part of the JRNP is closest to the mainland (around $30 \mathrm{~km}$ ) and the Gulf of Guacanayabo, with higher nutrient content than the Gulf of Ana Maria. Lluis Riera (1977) and Betanzos-Vega et al. (2012), suggest greater inputs rich in organic matter, nutrients and sediments from the mainland in the first gulf. The West sector of the archipelago is more than twice farther from the mainland than the East sector. According to Arriaza et al. (2008), the maximum speed of the currents in the ebb tide $(26 \mathrm{~cm} / \mathrm{s})$ and the flood tide $(13 \mathrm{~cm} / \mathrm{s})$, as calculated by hydrodynamic modeling on the SE Cuban platform, were located in the periphery of the confluence of the Gulf of Guacanayabo with the Gulf of Ana Maria. This suggests that the reef crests of the East sector of the JRNP may be subject to greater physical impacts from the sea, likely to increase with extreme weather events.

Although live A. palmata was documented in the reef crests in the entire park area, in the West sector there were abundant colonies with 100\% OM, especially those far from the tidal exchange channels, where the cays block the process. These standing dead colonies suggest the importance of old populations as habitat for other reef organisms (Martínez \& Rodríguez-Quintal, 2012).

An alternative explanation for the different distribution of Acropora spp. between the West and East sectors might be that the reef crests of the JRNP act as a barrier, a hypothesis already stated by González-Ferrer (2004). In fact, the pattern described through the 


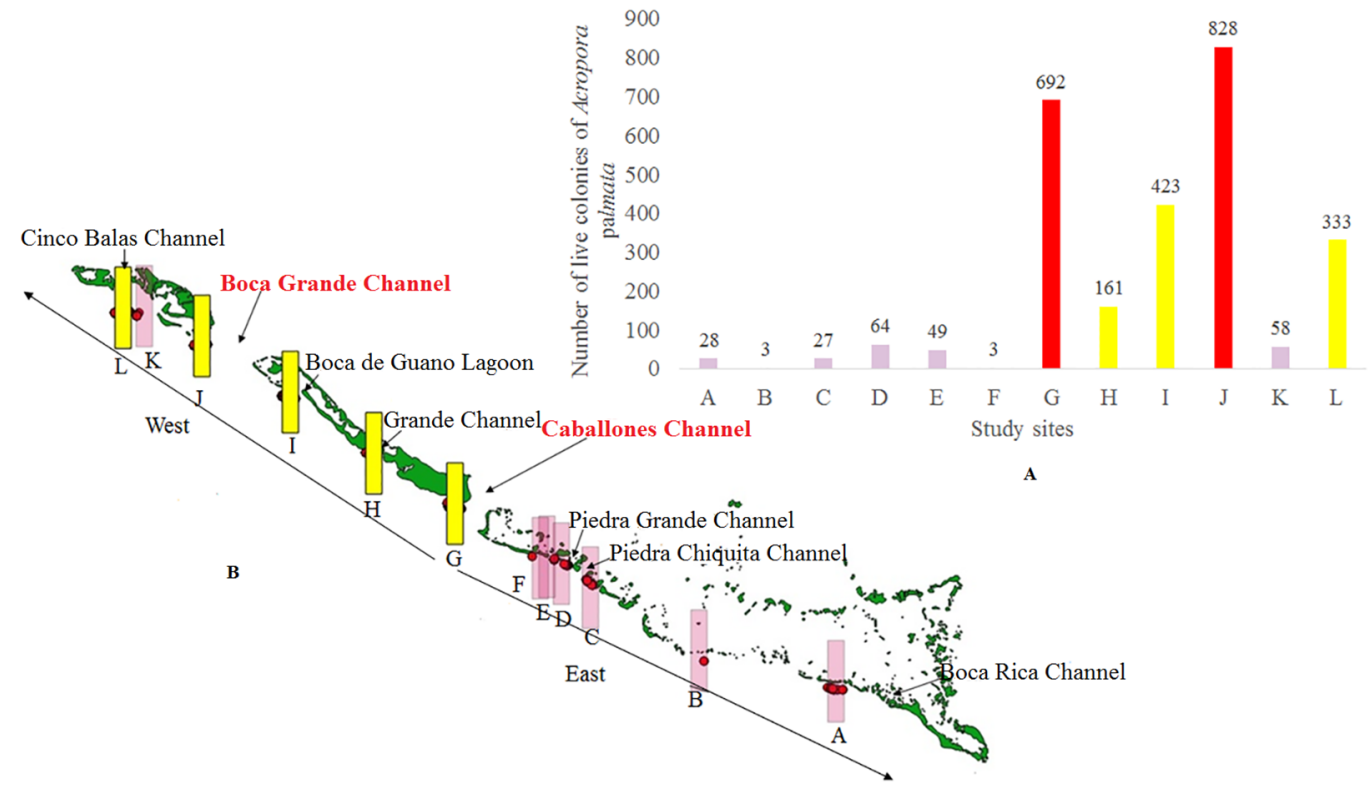

Figure 10 Number of colonies of Acropora palmata at 2,000 $\mathrm{m}$ from the channel located to the east in Jardines de la Reina National Park, Cuba. (A) In a graphic. (B) Location of all colonies.

Full-size $\underset{0}{0}$ DOI: 10.7717/peerj.6470/fig-10

GAM model (Fig. 8B) showed that the largest number of colonies (located between the chosen channels) were concentrated 2,000 m away from the eastern channels, where the ebb tide currents from the Gulf of Ana Maria may arrive with greater strength.

Due to the Coriolis Effect, the ebb tide currents tend to deviate to the right (west of the cays) and this influence may keep an ideal balance for reef stability in terms of nutrient content, light and organic matter. This behavior is present even further in the channels with greater exchange such as Caballones (approximately three $\mathrm{km}$ wide) and Boca Grande (approximately eight km wide) (Fig. 10). The aggregated pattern suggested by the spatial analysis is consistent with the clustered distribution observed in the first $1,000 \mathrm{~m}$ from the east side of the channels. This corroborates its influence over the distribution of $A$. palmata, enhancing the density of colonies near these channels.

According to Iturralde-Vinent (pers. comm. Manuel Antonio Iturralde Vinent. 2017), the issue of whether the reef crests or the keys of the PNJR formed first is not resolved. The cays are regarded as an accumulation of sand bars that eventually united. Sand was transported by currents, swell or wind from the lagoon or seagrass beds located between the cays and the reef crests. Based on this concept, the reefs must have formed almost simultaneously with or just before the cays began to form in the Upper Pleistocene to the Holocene. In the Caribbean, the first reefs were formed during the Oligocene, reaching a development peak during the Miocene (field observation of Iturralde-Vinent in GonzálezFerrer, 2004). However, the first record of Acropora spp. as a dominant reef structure dates back to the Late Oligocene (Wallace \& Rosen, 2006).

There was no evidence that reserve zones influence Acropora spp. populations. Diving sites with higher activity and tourism infrastructure are in RC (where protection is 
more effective). However, A. palmata (the only species present in all reserve zones) has a larger number of live colonies in RW and REW (West sector), where protection levels are lower. There were A. cervicornis populations only in RW (in critical status) and REW. A. prolifera populations were also found in higher numbers in these regions, and were healthier than any other species. According to Hernández-Fernández et al. (2016) local SCUBA diving does not affect Acropora spp. populations, as it is performed 8-22 m deep (far from shallow Acropora spp. populations).

The differences in the distribution of live colonies of Acropora spp. could be the result of propagation of larvae from $A$. palmata populations located further east than those zones where Acropora spp. is scarce (RC, RE and REE). Marine currents mainly flow from East to West and can limit the arrival of new larvae. It is also likely that substratum differences are the cause of different recruitment rates and/or post-settlement different mortality across the sites Zubillaga et al. (2008).

According to McField \& Kramer (2008) and based on the RM health indicator, A. palmata populations would have been in a "Red Alarm" state in RC and RW, while according to Alcolado \& Durán (2011) their health would have been regarded as normal. However, the status of A. cervicornis was critical and in "Red Alarm" as well. Regarding health status of the three species, A. cervicornis was the worst and A. prolifera (with few colonies in the PNJR) was the best.

Fogarty (2012) stated that in some Caribbean sites, A. prolifera was found in densities equivalent to or higher than those of at least one were of the parental species. In the JRNP, A. prolifera only represented $1.4 \%$ of all colonies, something similar to that of A. cervicornis (3.5\%). A decrease in the parental species, together with changes in the environment, can affect the frequency of hybridization (Fogarty, 2012), which demands further protection and conservation efforts in the case of $A$. cervicornis.

The WBD has been strongly related to thermal stresses resulting from climate change and seemed to proliferate on Acropora spp. (Randall \& van Woesik, 2015). WPD has been suggested as the principal cause of mass mortality of $A$. palmata within the FKNMS (Patterson et al., 2002). In our study, the impacts of WBD and WPD in colonies of A. palmata were low, $0.3 \%$ and $1.3 \%$ respectively, similar to those reported by Larson et al. (2014) for the reefs of Veracruz (Gulf of Mexico). WBD disease impact was low in the PNJR when compared with results found by Zubillaga et al. (2008) at Los Roques National Park (between 0.39\% and 4.69\%). However, RM was high (9\%) when compared to that obtained by Schelten et al. (2006) (1.33\%) for the populations of the southern coast of the Turks and Caicos Islands. RM was higher than that reported by Rey-Villiers et al. (2016) for all coral species in the crests of the PNJR in 2001 and $2012(\geq 2 \%)$.

In their study of the reefs of Cuba, Alcolado et al. (2003) stated that the species A. palmata showed high mortality along the northern and southern coasts of the island. Rey-Villiers et al. (2016) compared some results from the CUBAGRA Project with their 2012 results, and found that OM (for all coral species) was higher in 2012 than in 2001, with prevalence of young corals. Rey-Villiers et al. (2016) stated that in 2001coral cover was low in reef crests, using as a reference the high mortality of A. palmata populations. Nevertheless, the authors attributed certain recovery of the species to 
"over-sheeting". Bruckner (2002) suggested some evidence of recovery (e.g., southern coast of Cuba), where stable populations were found. Claro (2007) explained that instead of growing and branching independently, in Cuba, new corals of this species were growing on the large skeletons of dead corals, which favored faster recovery. Taking into account references, previous studies and our results, we can infer that a certain recovery of A. palmata populations has occurred in the PNJR.

According to Jaap (2002), within the morphometric measurements of A. palmata, a very large colony is considered one that reaches $400 \mathrm{~cm}$ in diameter among the tips of the most distal branches. In this study, colonies larger than $500 \mathrm{~cm}$ were counted,

but none reached the maximum diameter of $1,000 \mathrm{~cm}$, as reported for the Montecristi Barrier Reef National Park in the Dominican Republic (Geraldes, 2002). Colonies from 51 to $100 \mathrm{~cm}$ were predominant in the JRNP. Taking into account the scale suggested by Rogers et al. (2002) to establish the size of $A$. palmata ( small $=0-25 \mathrm{~cm}$, medium $=26-100 \mathrm{~cm}$, large $=>100 \mathrm{~cm}$ ), the colonies that prevailed in the JRNP can be classified as medium-sized. This can be considered additional evidence that A. palmata populations had been recovering from possible impacts experienced during the 1980s; similar behavior detected by Zubillaga, Bastidas \& Croquer (2005) in A. palmata at Los Roques National Park.

Assuming that the A. palmata colonies of the JRNP have a similar growth rate than that estimated by Jaap (2002) for the Florida reefs (between $4 \mathrm{~cm}$ and $11 \mathrm{~cm}$ per year), and by Quevedo (2002) in Puerto Rico (from 5 to $10 \mathrm{~cm}$ per year), the recovery of this species dates back to approximately 10-25 years. According to Rey-Villiers et al. (2016), and to the research experience of the authors in Jardines de la Reina, the recovery of $A$. palmata started $10-16$ years ago.

The recovery period of $A$. palmata can also be corroborated by the thesis presented by Baisre (2006) on the drastic reduction of nitrogen contribution to Cuban coastal waters that took place during the early 1990s and suggests the oligotrophication of these waters. The reports of nutrient loads in the region, which began in the 1960s, contained typical levels of oligotrophic waters $(0.11-0.20 \mu \mathrm{M}$ of Soluble Reactive Phosphorus, $0.20 \mu \mathrm{M}$ of Dissolved Inorganic Nitrogen and $4.6 \mu \mathrm{M}$ of Soluble Reactive Silicate) and may have increased in the 1980s due to greater use of fertilizers in Cuba, although there is no evidence of the possible increase of such nutrients. After the year 2000, nutrient levels in the waters of the JRNP have only been assessed in specific sites and not in the entire park area. In 2013, stations located at the Caballones Channel showed Soluble Reactive Phosphorus levels of $0.28 \mu \mathrm{M}, 3.3 \mu \mathrm{M}$ Dissolved Inorganic Nitrogen and $4.7 \mu \mathrm{M}$ Soluble Reactive Silicate.

The apparent recovery of $A$. palmata might be the result of the lack of severe anthropogenic impacts (sedimentation, coastal development, sewage, etc.), hurricanes, storms, and emerging coral diseases (white pox and necrosis), recognized as major threats to the populations of the Florida Keys, Venezuela and the US Virgin Islands (Patterson et al., 2002; Bythell, Pantos \& Richardson, 2004; Patterson \& Ritchie, 2004; Rogers, Sutherland \& Porter, 2005; Zubillaga et al., 2008). 


\section{CONCLUSIONS}

The results presented in this work provide basic data for future research on the status of Acropora spp. populations in the JRNP, where recovery of A. palmata has been observed. Knowledge of the species status and possible threats to the populations of Acropora spp. can inform decision makers and other actors to develop and implement conservation actions in the park. Such efforts should also include A. cervicornis.

\section{ACKNOWLEDGEMENTS}

Our special thanks to the Working Group of Sweet-Spa (crew of the "Oceans For Youth” vessel) and to Evelio A. Alemán, Yunier Marín and Maydel Marina from Marlin Azulmar, as well as to Víctor M. Portales Dima, Adrián Fasta Serrano, Leonel Hernández Cabrera, Maysel Miranda de León and Eliany González Prado, from the Coastal Ecosystem Research Center (CIEC). Thanks to Vicente Osmel Rodriguez Cárdenas for English revision. Finally, we want to acknowledge the work of the editor and the anonymous reviewers for their constructive comments on earlier drafts of the manuscript.

\section{ADDITIONAL INFORMATION AND DECLARATIONS}

\section{Funding}

The authors received funding from the "Biological diversity and connectivity between the Jardines de la Reina Archipelago and the Gulf of Ana María, Cuba" (P211LH005-031) project. The funders had no role in study design, data collection and analysis, decision to publish, or preparation of the manuscript.

\section{Grant Disclosures}

The following grant information was disclosed by the authors:

"Biological diversity and connectivity between the Jardines de la Reina Archipelago and the Gulf of Ana María, Cuba”: P211LH005-031.

\section{Competing Interests}

The authors declare that they have no competing interests.

\section{Author Contributions}

- Leslie Hernández-Fernández conceived and designed the experiments, performed the experiments, analyzed the data, prepared figures and/or tables, authored or reviewed drafts of the paper, approved the final draft.

- Roberto González de Zayas performed the experiments, analyzed the data, contributed reagents/materials/analysis tools, prepared figures and/or tables, authored or reviewed drafts of the paper.

- Yunier M. Olivera conceived and designed the experiments, performed the experiments, analyzed the data, contributed reagents/materials/analysis tools, analysis in Moran's I correlogram and software R 3.4.3. 
- Fabián Pina Amargós conceived and designed the experiments, performed the experiments, data collection.

- Claudia Bustamante López performed the experiments, data collection.

- Lisadys B. Dulce Sotolongo performed the experiments, data collection.

- Fernando Bretos performed the experiments, contributed reagents/materials/analysis tools, authored or reviewed drafts of the paper, english translate.

- Tamara Figueredo Martín performed the experiments, data collection.

- Dayli Lladó Cabrera performed the experiments, data collection.

- Francisco Salmón Moret performed the experiments, support for Analysis in Moran's I correlogram.

\section{Data Availability}

The following information was supplied regarding data availability:

The raw data is available in the Supplemental File.

\section{Supplemental Information}

Supplemental information for this article can be found online at http://dx.doi.org/10.7717/ peerj.6470\#supplemental-information.

\section{REFERENCES}

Acropora Biological Review Team. 2005. Atlantic Acropora Status Review Document. Report to National Marine Fisheries Service, Southeast Regional Office. St. Petersburg: National Marine Fisheries Service, Southeast Regional Office, 152 p + App

Alcolado PM, Claro-Madruga R, Menéndez-Macías G, García Parrado P, Martínez-Daranas B, Sosa M. 2003. The Cuban coral reefs. In: Cortés J, ed. Latin American Coral Reefs. Amsterdam: Elsevier, 53-75.

Alcolado PM, Durán A. 2011. Sistema de escalas para la clasificación y puntaje de condición del bentos e ictiofauna de arrecifes coralinos de Cuba y del Gran Caribe. Serie Oceanológica 8:25-29.

Álvarez-Filip L, Dulvy NK, Gill JA, Côté IM, Watkinson AR. 2009. Flattening of Caribbean coral reefs: region-wide declines in architectural complexity. Proceedings of the Royal Society B: Biological Sciences 276(1669):3019-3025 DOI 10.1098/rspb.2009.0339.

Aronson R, Bruckner A, Moore J, Precht B, Weil E. 2008. Acropora palmata. The IUCN red list of threatened species 2008: e.T133006A3536699.

DOI 10.2305/IUCN.UK.2008.RLTS.T133006A3536699.en (accessed 26 June 2017).

Aronson BR, Precht FW. 2001. White-band disease and the changing face of Caribbean coral reefs. Hydrobiologia 460(1/3):25-38 DOI 10.1023/A:1013103928980.

Arriaza L, Simanca J, Rodas L, Lorenzo S, Hernández M, Linares EO, Milian D, Romero P. 2008. Corrientes marinas estimadas en la plataforma suroriental cubana. Serie Oceanológica 4:1-10.

Baisre JA. 2006. Assessment of nitrogen flows into the Cuban landscape. Biogeochemistry 79(1-2):91-108 DOI 10.1007/s10533-006-9004-z.

Baddeley RA, Rubak E, Turner R. 2015. Spatial point patterns: methodology and applications with R. Boca Raton: Chapman and Hall/CRC Press.

Besag J. 1977. Contribution to the discussion of Dr Ripley's paper. Journal of the Royal Statistical Society: Series B 39:193-195. 
Betanzos-Vega A, Garcés-Rodríguez Y, Delgado-Miranda G, Pis-Ramírez MA. 2012. Variación espacio-temporal y grado de eutrofia de sustancias nutrientes en aguas de los golfos de Ana María y Guacanayabo, Cuba. Revista Ciencias Marinas y Costeras 4:117-130 DOI 10.15359/revmar.4.8.

Bjornstad ON. 2016. ncf: spatial nonparametric covariance functions. R Package Version 1:1-7. Available at https://mran.microsoft.com/snapshot/2014-11-17/web/packages/ncf/index.html.

Bruckner AW. 2002. Proceedings of the Caribbean Acropora Workshop: Potential Application of the U.S. Endangered Species Act as a Conservation Strategy. NOAA Technical Memorandum NMFS-OPR-24, Silver Spring, MD, 184 pp.

Bruckner AW. 2003. Proceedings of the Caribbean Acropora workshop: potencial application of the U.S. Endangered Species Act as a conservation Strategy. NOAA Technical Memorandum NMFS-OPR-24, Silver Spring, MD, 199 pp.

Burnham KP, Anderson DR. 2002. Model selection and multimodel inference: a practical information-theoretic approach. New York: Springer.

Bythell J, Pantos O, Richardson L. 2004. White plague, white band, and other "white" diseases. In: Rosenberg E, Loya Y, eds. Coral Health and Disease. Berlin: Springer, 351-366.

Claro R, Lindeman KC, Parenti LR. 2001. Ecology of the marine fishes of Cuba. Washington: Smithsonian Institution.

Claro R. 2007. La Biodiversidad marina de Cuba. La Habana: Instituto de Oceanología, Ministerio de Ciencia, Tecnología y Medio Ambiente, La Habana, Cuba, CD-ROM.

Croquer A, Cavada-Blanco F, Zubillaga AL, Agudo-Adriani EA, Sweet M. 2016. Is Acropora palmata recovering? A case study in Los Roques National Park, Venezuela. PeerJ 4(1):e1539 DOI 10.7717/peerj.1539.

Devine B, Loomis C, Rogers C. 2002. Mapping marine populations. In: Bruckner AW, ed. Proceedings of the Caribbean Acropora Workshop: Potential Application of the U.S. Endangered Species Act as a Conservation Strategy. NOAA Technical Memorandum NMFSOPR-24. Silver Spring: NOAA, 145 pp.

Fogarty ND. 2012. Caribbean acroporid coral hybrids are viable across life history stages. Marine Ecology Progress Series 446:145-159 DOI 10.3354/meps09469.

Geraldes FX. 2002. Status of the Acroporid coral species in the Dominican Republic. In: Bruckner AW, ed. Proceedings of the Caribbean Acropora Workshop: Potential Application of the U.S. Endangered Species Act as a Conservation Strategy. NOAA Technical Memorandum NMFS-OPR-24. Silver Spring: NOAA, 137 pp.

González de Zayas R, Zúñiga-Ríos A, Camejo-Cardoso O, Batista-Tamayo LM, Cardenas-Murillo R. 2006. Atributos físicos del ecosistema Jardines de la Reina. En: Ecosistemas Costeros: Biodiversidad y gestión de recursos naturales. Compilación por el XV Aniversario del CIEC. Sección II. Ecosistema Jardines de la Reina. CIEC. CUJAE.

González-Ferrer S. 2004. Corales pétreos, jardines sumergidos de Cuba. La Habana, Cuba: Editorial Academia.

Graham MH. 2003. Confronting multicollinearity in ecological multiple regression. Ecology 84(11):2809-2815 DOI 10.1890/02-3114.

Hahn U. 2012. A studentized permutation test for the comparison of spatial point patterns. Journal of the American Statistical Association 107(498):754-764 DOI 10.1080/01621459.2012.688463.

Hernández-Fernández L, Bustamante-López C. 2017. Condición de la población de Acropora palmata Lamarck, 1816 en arrecifes del Parque Nacional Jardines de la Reina, Cuba. Revista Investigaciones Marinas 36:79-91. 
Hernández-Fernández L, Bustamante-López C, Dulce-Sotolongo LB. 2016. Estado de crestas de arrecifes en el Parque Nacional Jardines de la Reina, Cuba. Revista Investigaciones Marinas 36:79-91.

Hernández-Fernández L, Olivera Espinosa YM, Figueredo-Martín T, Gómez Fernández R, Brizuela-Pardo L, Pina-Amargós F. 2016. Incidencia del buceo autónomo y capacidad de carga en sitios de buceo del Parque Nacional Jardines de la Reina, Cuba. Revista Ciencias Marinas y Costeras 8(2):9-27 DOI 10.15359/revmar.8-2.1.

Jaap WC. 2002. Acropora-A review of systematic, taxonomy, abundance, distribution, status, and trends. In: Bruckner AW, ed. Proceedings of the Caribbean Acropora Workshop: Potential Application of the U.S. Endangered Species Act as a Conservation Strategy. Silver Spring, MD: Miami Florida. NOAA Technical Memorandum NMFS-OPR-24, 136-141.

Jackson J. 1977. Competition on marine hard substrata: the adaptive significance of solitary and colonial strategies. American Naturalist 111:743-767.

Jackson JBC. 1992. Pleistocene perspectives on coral reef community structure. American Zoology 32(6):719-731 DOI 10.1093/icb/32.6.719.

Jackson J, Donovan M, Cramer K, Lam V. 2014. Status and trends of Caribbean Coral Reefs: 1970-2012. Gland, Switzerland: Global Coral Reef Monitoring Network, IUCN, 304.

Larson EA, Gilliam DS, López Padierna M, Walker BK. 2014. Possible recovery of Acropora palmata (Scleractinia: Acroporidae) within the Veracruz Reef System, Gulf of Mexico: a survey of 24 reefs to assess the benthic communities. Revista de Biología Tropical 62:75-84 DOI 10.15517/rbt.v62i0.15903.

Lluis Riera M. 1977. Estudios hidrológicos de la plataforma Suroriental de Cuba y aguas adyacentes. Informe Científico. Técnico. No.16. Instituto de Oceanología de Cuba. Academia de Ciencias de Cuba.

Loh JM. 2008. A valid and fast spatial bootstrap for correlation functions. Astrophysical Journal 681(1):726-734 DOI 10.1086/588631.

Martínez K, Rodríguez-Quintal JG. 2012. Estructura poblacional de Acropora palmata (Scleractinia: Acroporidae) en el Parque Nacional San Esteban, Venezuela. Boletín del Instituto Oceanográfico de Venezuela 51:129-137.

McField MD, Kramer P. 2008. Arrecifes saludables. Una guía de referencia rápida. 26.

Miller MW, Kerr K, Williams DE. 2016. Reef-scale trends in Florida Acropora spp. abundance and the effects of population enhancement. PeerJ 4:e2523 DOI 10.7717/peerj.2523.

Muller EM, Rogers CS, Spitzack AS, van Woesik R. 2008. Bleaching increases likelihood of disease on Acropora palmata (Lamarck) in Hawksnest Bay, St John, US Virgin Islands. Coral Reefs 27(1):191-195 DOI 10.1007/s00338-007-0310-2.

Muller EM, Rogers CS, van Woesik R. 2014. Early signs of recovery of Acropora palmata in St. John, US Virgin Islands. Marine Biology 161(2):359-365 DOI 10.1007/s00227-013-2341-2.

National Marine Fisheries Service. 2014. Recovery Plan for Elkhorn (Acropora palmata) and Staghorn (A. cervicornis) Corals. Silver Spring, Maryland: Prepared by the Acropora Recovery Team for the National Marine Fisheries Service.

Patterson KL, Porter JW, Ritchie KB, Polson SW, Mueller E, Peters EC, Santavy DL, Smith GW. 2002. The etiology of white pox, a lethal disease of the Caribbean elkhorn coral, Acropora palmata. Proceedings of the National Academy of Sciences of the United States of America 99(13):8725-8730 DOI 10.1073/pnas.092260099.

Patterson KL, Ritchie KB. 2004. White pox disease of the Caribbean elkhorn coral, Acropora palmata. In: Rosenberg E, Loya Y, eds. Coral Health and Disease. Berlin: Springer, 289-297. 
Pina-Amargós F, González-Sansón G, Martín-Blanco F, Valdivia A. 2014. Evidence for protection of targeted reef fish on the largest marine reserve in the Caribbean. PeerJ 2(1):e274 DOI $10.7717 /$ peerj.274.

Pina-Amargós F, Hernández-Fernández L, Clero L, González-Sansón G. 2008. Características de los hábitats coralinos en Jardines de la Reina, Cuba. Revista Investigaciones Marinas 29:225-237.

QGIS Development Team. 2018. QGIS geographic information system. Open Source Geospatial Foundation.

Quevedo V. 2002. Appendix 3: letter to DNER on Acropora palmata populations at Steps Reef, Rincon. In: Bruckner AW, ed. Proceedings of the Caribbean Acropora Workshop: Potential Application of the U.S. Endangered Species Act as a Conservation Strategy. Silver Spring, MD: Miami Florida. NOAA Technical Memorandum NMFS-OPR-24, 89-94.

Randall CJ, van Woesik R. 2015. Contemporary white-band disease in Caribbean corals driven by climate change. Nature Climate Change 5(4):375-379 DOI 10.1038/nclimate2530.

R Core Team. 2017. R: a language and environment for statistical computing. Viena, Austria: R Foundation for Statistical Computing. Available at: https://www.R-project.org/.

Rey-Villiers N, Alcolado-Prieta P, Busutil L, Caballero H, Perera-Pérez O, HernándezFernández L, González-Díaz P, Alcolado MP. 2016. Condición de los arrecifes coralinos del golfo de Cazones y el archipiélago Jardines de la Reina, Cuba: 2001-2012. In: Rey-Villiers N, ed. Línea base ambiental para el estudio del cambio climático en el golfo de Cazones y el archipiélago Jardines de la Reina, Cuba. La Habana, Cuba: Instituto de Oceanología, CITMA, 93-146.

Rodríguez-Martínez RE, Banaszak AT, McField MD, Beltrán-Torres AU, Álvarez-Filip L. 2014. Assessment of Acropora palmata in the Mesoamerican reef sSystem. PLOS ONE 9(4):e96140 DOI 10.1371/journal.pone.0096140.

Rogers C, Gladfelter W, Hubbard D, Gladfelter E, Bythell J, Dunsmore R, Loomis C, Devine B, Hillis-Starr Z, Phillips B. 2002. Acropora in the U.S. Virgin Islands: a wake or an awakening? A status report prepared for the national oceanographic and atmospheric administration. In: Bruckner AW, ed. Proceedings of the Caribbean Acropora Workshop: Potential Application of the U.S. Endangered Species Act as a Conservation Strategy. Silver Spring: Miami Florida. NOAA Technical Memorandum NMFS-OPR-24, 95-118.

Rogers C, Sutherland KP, Porter JW. 2005. Has white pox disease been affecting Acropora palmata for over 30 years? Coral Reefs 24(2):194-194 DOI 10.1007/s00338-004-0470-2.

Roth L, Muller EM, van Woesik R. 2013. Tracking Acropora fragmentation and population structure through thermal-stress events. Ecological Modelling 263:223-232

DOI 10.1016/j.ecolmodel.2013.05.002.

Schelten CH, Brown S, Gurbisz CB, Kautz B, Lentz JA. 2006. Status of Acropora palmata populations off the Coast of South Caicos, Turks and Caicos Islands. $57^{\text {th }}$ Gulf and Caribbean Fisheries Institute 57:665-678.

Vollmer SV, Palumbi SR. 2002. Hybridization and the evolution of reef coral diversity. Science 296(5575):2023-2025 DOI 10.1126/science.1069524.

Wallace CC, Rosen BR. 2006. Diverse staghorn corals (Acropora) in high-latitude Eocene assemblages: implications for the evolution of modern diversity patterns of reef corals. Proceedings of the Royal Society B: Biological Sciences 273(1589):975-982 DOI 10.1098/rspb.2005.3307.

Weil E, Hooten AJ. 2008. Underwater cards for assessing coral health on Caribbean reefs. CRTR. St. Lucia: Program Project Executing Agency, Centre for Marine Studies, The University of Queensland. 
Williams DE, Miller MN, Kramer KL. 2006. Demographic monitoring protocols for threatened Caribbean Acropora spp. corals. NOAA Technical Memorandum NMFS-SEFSC-543, 91.

Yee TW. 2015. Vector generalized linear and additive models: with an implementation in $R$. New York: Springer.

Yee TW, Wild CJ. 1996. Vector generalized additive models. Journal of the Royal Statistical Society Series B 58:481-493.

Zlatarski VN, Martínez-Estalella N. 1980. Escleractinios de Cuba con datos sobre sus organismos asociados (en ruso). Sofía: Editorial Academia de Bulgaria.

Zubillaga AL, Bastidas C, Croquer A. 2005. High densities of the Elkhorn coral Acropora palmata in Cayo de Agua, Archipelago Los Roques National Park, Venezuela. Coral Reefs 24(1):86-86 DOI 10.1007/s00338-004-0458-y.

Zubillaga AL, Márquez LM, Croquer A, Bastidas C. 2008. Ecological and genetic data indicate recovery of the endangered coral Acropora palmata in Los Roques, Southern Caribbean. Coral Reefs 27(1):63-72 DOI 10.1007/s00338-007-0291-1.

Zuur AF, Ieno EN, Walker NJ, Saveiliev AA, Smith GM. 2009. Mixed effects models and extensions in ecology with $R$. New York: Springer. 